\title{
EVALUATION OF PURIFIED PROTEIN DERIVATES TEST AT TUBERCULOSIS DISPENSARY IN HATAY, TURKEY, APPLIED TO TURKS AND SYRIAN REFUGEES (2012-2015)
}

\author{
Nazan Savaş ${ }^{1}$, Gülnur Barutcu², Arif Yeniçeri ${ }^{1}$ \\ 'Department of Public Health, Medical Faculty, Mustafa Kemal University, Antakya, Hatay, Turkey \\ ${ }^{2}$ Hatay Merkez Tuberculosis Dispensary, Hatay Provincial Directorate of Public Health, Hatay, Turkey
}

\section{SUMMARY}

Objective: The aim of the study was to evaluate results of purified protein derivates (PPD) test applied at the Tuberculosis Dispensary between 2012-2015 in Hatay, Turkey, where a large number of Syrian refugees have migrated since the Syrian civil war began in 2011.

Methods: PPD test records from the Electronic Tuberculosis Management System at the Tuberculosis Dispensary from 2012-2015 were analyzed based on nationality, age groups, BCG scar availability, and PPD reaction. The annual risk of tuberculosis infection (ARTI) was calculated based on years for each age group in Turks and Syrian refugees and the trend was evaluated. Student-t, Chi-square, and Mantel-Haenszel tests were used in statistical analyses, $p<0.05$ was considered significant.

Results: In total, 5,255 PPD tests were made, $15.5 \%$ were Syrian refugees. BCG scar was missing in $48.5 \%$ of Turks and $87.3 \%$ of refugees $(p<0.001)$. The $0-5$ age group represented the lowest rate (Turks 3.2\%, refugees $4.3 \%$ ) and the 19-64 age group represented the highest rate (Turks 51.1\%, refugees $54.1 \%$ ) of positive PPD reaction among individuals without BCG scar. Among individuals without BCG scar, more positive PPD reactions developed in refugees of the $6-18$ group than in Turks (Turks $16.9 \%$, refugees $46.4 \%, p<0.001$ ). Among individuals with BCG scar, more positive PPD reactions developed among refugees of the $0-5$ (Turks $7.8 \%$, refugees $24.0 \%, p=0.049$ ) and $19-64$ (Turks $36.6 \%$, refugees $58.8 \%, p=0.028$ ) age groups. ARTIs between $2012-2015$ were $0.2 \%, 1.0 \%, 1.3 \%$, and $1.4 \%$ among Turks, (except 2012) $2.3 \%, 0.3 \%, 2.4 \%$ among refugees in the $0-5$ age group, $1.1 \%, 2.0 \%, 1.7 \%$, and $1.5 \%$ among Turks, and $8.5 \%, 6.6 \%, 7.3 \%$, and $2.4 \%$ among refugees in the $6-18$ age group, respectively.

Conclusion: Higher positive PPD reactions and ARTIs were found among Syrian refugees, more specifically in the 6-18 age group.

Key words: tuberculosis, Syrian refugee, Turkey

Address for correspondence: N. Savaş, Department of Public Health, Medical Faculty, Mustafa Kemal University, Antakya, 31000 Hatay, Turkey. E-mail: drnazansavas@hotmail.com

https://doi.org/10.21101/cejph.a5012

\section{INTRODUCTION}

According to the Global Tuberculosis Report 2015, 1,5 million deaths and 6 million new cases occurred in the world in 2014, and $37 \%$ of new tuberculosis (TB) cases had remained undiagnosed or unreported (1).

Most people with latent TB infection (LTBI) have no signs or symptoms of TB disease and are not infectious (2). TB cases develop from a large and widely distributed reservoir of latent infection, the true incidence of TB does not usually vary greatly across small areas or short periods of time (less than 5 years) (3).

LTBI is defined as the presence of immune responses to mycobacterium tuberculosis antigens without clinical evidence of active TB (2). Despite the fact that certain new methods have been developed recently with the aim of investigating the presence of LTBI, there is not a gold standard method used in the diagnosis of LTBI and tuberculosis skin test (TST) is still widely used (4, 5). According to Guidelines on the Management of LTBI issued by WHO in 2015 for high-income countries and upper-middleincome countries where incidence is under 100 out of one hundred thousand, risk groups that are required to be systematically screened and treated appear to be the adults and children who have been recently in contact with pulmonary TB patients, HIV $\left.{ }^{+}\right)$people, patients who are to get anti-tumor necrosis factor (anti-TNF) treatment, patients on dialysis, patients who are going to have solid organ or bone marrow transplantation, and patients with silicosis (4). Apart from these risk groups, LTBI screening can also be at stake for prisoners, health workers, those who migrated from the countries with high TB incidence, homeless people, and illegal drug addicts. TST or interferon gamma release tests (IGRA) can be applied in diagnosis for both groups. Those who are prior in terms of LTBI screening in low-income countries and countries with the incidence over 100 out of one hundred thousand are HIV (+) people, children who are under the age of 5 and in family contact or a close contact with active pulmonary tuberculosis patients. TST application has been recommended for 
these countries (6). Maintenance of TST has also been recommended in TB Diagnosis and Treatment Guidelines published in 2011 in Turkey by the Ministry of Health (7).

TST does not provide information about the disease but only shows whether the person has been infected with the bacillus or not (8). Although the value of the test has been substantially decreased with the use of BCG vaccine, it is still the most valuable and at the same time simple and inexpensive method to identify newly infected cases, future risk of infection in a country, and the annual risk of tuberculosis infection (ARTI). Moreover, the tuberculin survey still remains an epidemiological tool to evaluate TB trends (3). Especially young children are the preferred target group for TST-surveys as their ARTI estimates correlate better with the recent TB situation in the target community, and sequential ARTI estimates from repeated surveys may be useful for measuring the trend of TB transmission $(9,10)$. ARTI is the probability of becoming infected within a year for persons of particular age group in a society not infected with TB. ARTI studies are easier and more objective than tuberculosis prevalence and incidence since they are conducted with TST and are not influenced by case detection and recording (11).

The aim of this research is to determine the results of TST applied between the years 2012-2015 at the Tuberculosis Dispensary (TD) in Hatay, to where many Syrian refugees have migrated since the Syrian civil war began in 2011, according to years, gender, age groups, nationality (Turkish/Syrian), and to evaluate the trends of ARTIs over years according to the age groups of both nationalities.

\section{MATERIALS AND METHODS}

This cross-sectional study was made in 2016 at the Tuberculosis Dispensary (TD) in Hatay Merkez. Hatay is a province located in Turkey's Eastern Mediterranean Region on the border with Syria and has populations of 1,533,507 Turks and 402,000 Syrian refugees $(12,13)$. There are two TDs in Hatay, and the population of Hatay Merkez, the region where the TD of the study is found, is 973,475 .

TST (purified protein derivates, PPD) records of the Electronic Tuberculosis Management System (ETMS) at TD from 2012-2015 were evaluated retrospectively in the research. PPD records were first compared based on the nationality and analyzed according to age, gender, BCG scar (vaccine) status, the diameter of induration, and PPD reaction. Regarding the evaluation, PPD reaction was analyzed based on the nationality of each age group among people with and without BCG vaccine using the classification shown in Table 1.

Later on, ARTIs and ARTI change rates between 2012-2015 were calculated separately for each age group (0-5, 6-18, 19-64, and over 65) among Turks and Syrians. In calculating ARTI, the ARTI $=1-\mathrm{N} 1 / \mathrm{y}$ formula was used $(\mathrm{N}-$ ratio of PPD negatives in particular age; $\mathrm{y}$ - average age of particular age group) (14).

Regarding statistical analyses, ARTIs were calculated using Excel and SPSS.19 package program; frequency tables, descriptive statistics, Student-t, Chi-square, and Mantel-Haenszel tests were made; $\mathrm{p}<0.05$ was considered significant. Permissions for the research were obtained from the Mustafa Kemal University Clinical Research Ethics Committee and Hatay Public Health Directorate.
Table 1. Diagnoses based on PPD diameter of induration among people with and without BCG vaccine

\begin{tabular}{|l|l|}
\hline \multicolumn{2}{|l|}{ With BCG vaccine } \\
\hline $0-5 \mathrm{~mm}$ & Negative \\
\hline $6-14 \mathrm{~mm}$ & BCG positivity \\
\hline $15 \mathrm{~mm}$ and above & Positive, infection positive \\
\hline Without BCG vaccine & \\
\hline $0-5 \mathrm{~mm}$ & Negative \\
\hline $6-9 \mathrm{~mm}$ & Suspicious reaction ${ }^{\mathrm{a}}$ \\
\hline $10 \mathrm{~mm}$ and above & Positive \\
\hline
\end{tabular}

aTest is repeated after a week; it is considered negative if the diameter of induration is $6-9 \mathrm{~mm}$ and suspicious if it is $\geq 10 \mathrm{~mm}$. Within next $7-14$ days, test is repeated. It is considered negative if it is found $6-9 \mathrm{~mm}$ again; and it is considered positive if it is determined to be $\geq 10 \mathrm{~mm}$.

\section{RESULTS}

According to the records of Hatay Merkez TD ETMS, 5,255 PPD tests were made between January 2012 - December 2015, $15.5 \%$ (815) of them were Syrian refugees. Frequency distribution according to the years and nationality is shown in Table 2.

The results show that $51.2 \%$ of the people who were applied PPD test were women, $48.3 \%$ of Turks and $55.6 \%$ of Syrian refugees were women $(p<0.001)$ (Table 3$)$. As to the evaluation based on age groups, $23.2 \%$ of them fell into the $0-5$ age group, $22.9 \%$ were in the $6-18$ age group, $50.0 \%$ were in the 19-64 age group, and $3.9 \%$ were over 65 years. Differences were found within the distribution of age groups made according to nationality, $14.9 \%$ of Turks were in the $0-5$ age group, while $68.7 \%$ of Syrian refugees fell within that age group $(\mathrm{p}<0.001)$.

It was found that $55.9 \%$ of the people who were applied PPD were lacking BCG scar, $40.4 \%$ had one scar, 3.2\% had two, and $0.5 \%$ had three scars. When it was evaluated based on the nationality, results indicate that there was not any BCG scar, that is the vaccine, in $48.5 \%$ of Turks and $87.3 \%$ of Syrian refugees $(\mathrm{p}<0.001)$. Syrian refugees who did not have BCG vaccine were found to be greater in number for all age groups except for the $65+$ age group $(\mathrm{p}<0.001)$.

After PPD indurations occurred in $46.1 \%$ of the people without BCG vaccine and in $77.8 \%$ of the ones with BCG vaccine. The average diameter of induration turned out to be $10.83 \pm 7.35 \mathrm{~mm}$ for the people who were lacking BCG vaccine, whereas it was found to be $12.01 \pm 6.27 \mathrm{~mm}$ for the ones with BCG vaccine.

Table 2. Distribution based on years and nationality among people who were applied PPD $(N=5,255)$

\begin{tabular}{|l|c|c|c|}
\hline Year & $\begin{array}{c}\text { Turkish citizen } \\
\mathbf{n}\left(\%^{\mathrm{a}}\right)\end{array}$ & $\begin{array}{c}\text { Syrian refugee } \\
\mathbf{n}\left(\%^{\mathrm{a}}\right)\end{array}$ & $\begin{array}{c}\text { Total } \\
\mathbf{N}\left(\%^{\mathrm{b}}\right)\end{array}$ \\
\hline 2012 & $760(97.9)$ & $16(2.1)$ & $776(14.8)$ \\
\hline 2013 & $759(79.6)$ & $194(20.4)$ & $953(18.1)$ \\
\hline 2014 & $1,531(84.4)$ & $284(15.6)$ & $1,815(34.5)$ \\
\hline 2015 & $1,390(81.2)$ & $321(18.8)$ & $1,711(32.6)$ \\
\hline Total & $4,440(84.5)$ & $815(15.5)$ & $5,255(100.0)$ \\
\hline
\end{tabular}

aPercentage of row, ${ }^{b}$ percentage of column 
Table 3. Gender, age and BCG scar distribution among people who were applied PPD based on nationality

\begin{tabular}{|c|c|c|c|}
\hline & $\begin{array}{c}\text { Turkish citizen } \\
\mathrm{n}\left(\%^{\mathrm{a}}\right)\end{array}$ & $\begin{array}{c}\text { Syrian refugee } \\
\mathrm{n}\left(\%^{\mathrm{a}}\right)\end{array}$ & $\mathrm{p}$-value \\
\hline \multicolumn{4}{|l|}{ Gender } \\
\hline Female & $2,276(48.3)$ & $526(55.6)$ & \multirow{2}{*}{$<0.001$} \\
\hline Male & $2,440(51.7)$ & $420(44.4)$ & \\
\hline \multicolumn{4}{|l|}{ Age group } \\
\hline $0-5$ & $701(14.9)$ & $650(68.7)$ & \multirow{4}{*}{$<0.001^{b}$} \\
\hline $6-18$ & $1,163(24.7)$ & $116(12.3)$ & \\
\hline $19-64$ & $2,649(56.2)$ & $170(18.0)$ & \\
\hline $65+$ years & $203(4.3)$ & $10(1.1)$ & \\
\hline \multicolumn{4}{|l|}{ BCG scar } \\
\hline Absent & $2,289(48.5)$ & $826(87.3)$ & \multirow{2}{*}{$<0.001^{c}$} \\
\hline Present & $2,427(51.5)$ & $120(12.7)$ & \\
\hline \multicolumn{4}{|l|}{$0-5$ age group } \\
\hline Without BCG scar & $556(79.3)$ & $611(94.0)$ & \multirow{2}{*}{$<0.001$} \\
\hline With BCG scar & $145(20.7)$ & $39(6.0)$ & \\
\hline \multicolumn{4}{|l|}{ 6-18 age group } \\
\hline Without BCG scar & $542(46.6)$ & $82(70.7)$ & \multirow{2}{*}{$<0.001^{b}$} \\
\hline With BCG scar & $621(53.4)$ & $34(29.3)$ & \\
\hline \multicolumn{4}{|l|}{ 19-64 age group } \\
\hline Without BCG scar & $1,057(39.9)$ & $125(73.5)$ & \multirow{2}{*}{$<0.001^{b}$} \\
\hline With BCG scar & $1,592(60.1)$ & $45(26.5)$ & \\
\hline \multicolumn{4}{|l|}{$65+$ age group } \\
\hline Without BCG scar & $134(66.0)$ & $8(80.0)$ & \multirow{2}{*}{$0.293^{b}$} \\
\hline With BCG scar & $69(34.0)$ & $2(20.0)$ & \\
\hline
\end{tabular}

aPercentage of column, ${ }^{\mathrm{b}} \mathrm{Chi}$ square test, ${ }^{\mathrm{c}}$ Mantel-Haenszel test

Regarding the evaluation of PPD reaction based on nationality in people with and without BCG vaccine, among the people with BCG vaccine, in $30.0 \%$ of Turks and $40.2 \%$ of the refugees the diameter of induration was measured to be $15 \mathrm{~mm}$ and more, which means that positive reaction developed $(p=0.124)$ (Table 4). As to the execution of this analysis for each age group separately; there was no statistical difference depending on the nationality detected in PPD reaction within the 6-18 age group ( $p=0.595$ ), while the $0-5$ and $19-64$ age groups were observed to show statistical differences in terms of PPD reactions $(\mathrm{p}=0.049$, $\mathrm{p}=0.028$ ). Concerning the $0-5$ age group, $7.8 \%$ of Turks and $24 \%$ of the refugees had a positive reaction, and within the 19-64 age group positive reaction developed in $36.6 \%$ of Turks and in $58.8 \%$ of the refugees.

Among the people without BCG vaccine, in $31.1 \%$ of Turks and $16.1 \%$ of the refugees the diameter of induration was measured to be $10 \mathrm{~mm}$ and above, which means that positive reaction developed ( $p<0.001)$. As to the execution of this analysis for each age group separately, no statistical differences depending on the nationality were found in terms of PPD reactions within the $0-5$, 19-64, and 65+ age groups ( $p>0.05$ ), while there was statistical difference detected within the $6-18$ age group $(p<0.001)$. In the $6-18$ age group, $16.9 \%$ of Turks and $46.4 \%$ of the refugees showed a positive reaction. Furthermore, among both Turks without vaccine and refugees without vaccine, the lowest rate of positive reaction development was found in the $0-5$ age group and the age group indicating the highest rate of positive reaction was the 19-64 age group. The rate of positive reaction was 3.2\% among Turks lacking vaccine and $4.3 \%$ among refugees lacking vaccine in the $0-5$ age group, and it was found to be $51.5 \%$ of Turks without vaccine and $54.1 \%$ of refugees without vaccine in the 19-64 age group.

Calculating ARTIs between the years 2012-2015 according to age groups of both nationalities among the people without BCG vaccine, ARTIs were found as 0.002, 0.010, 0.013 and 0.014 , respectively, in Turks falling into the $0-5$ age group (Fig. 1), they were calculated as 0.0, 0.023, 0.003 and 0.024 in Syrian refugees (Fig. 2). Moreover, in the 6-18 age group, they were calculated as $0.011,0.020,0.017$ and 0.015 among Turks and $0.085,0.066,0.073$ and 0.024 among Syrian refugees. As to the $19-64$ age group, the following values were found $0.020,0.023$, 0.013 and 0.017 among Turks and 0.018, 0.044, 0.024 and 0.010 among Syrian refugees.

\section{DISCUSSION}

Target tuberculin testing for LTBI is a major component of TB control which allows us to identify people at high risk or people at low risk whose future activity will put them at increased risk of exposure, of developing TB who would profit by treatment of LTBI if detected (15). A positive TST reaction may present LTBI,

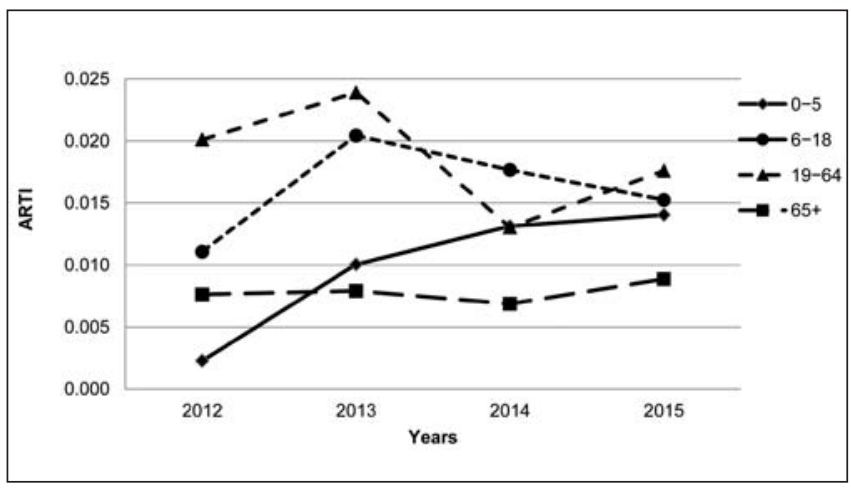

Fig. 1. ARTIs among Turks without BCG vaccine based on age groups (2012-2015).

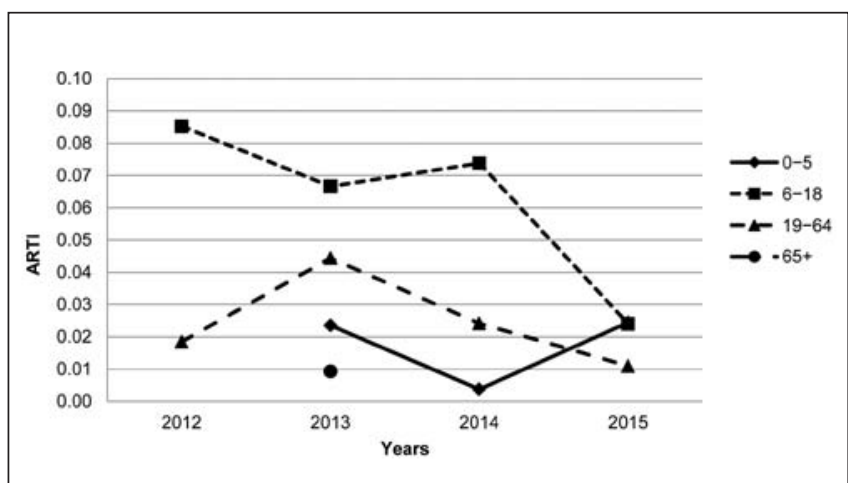

Fig. 2. ARTIS among Syrian refugees without BCG vaccine based on age groups (2012-2015). 
Table 4. Distribution of PPD reaction among the ones with and without BCG vaccine based on nationality

\begin{tabular}{|c|c|c|c|c|c|}
\hline Age group & PPD reaction & $\begin{array}{c}\text { Turkish citizen } \\
\mathrm{n}\left(\%^{\mathrm{a}}\right)\end{array}$ & $\begin{array}{c}\text { Syrian refugee } \\
n\left(\%^{a}\right)\end{array}$ & $\begin{array}{l}\text { Total } \\
\mathrm{N}\left(\%^{\mathrm{a}}\right)\end{array}$ & $\mathrm{p}$-value ${ }^{\mathrm{b}}$ \\
\hline \multicolumn{6}{|c|}{ With BCG vaccine } \\
\hline \multirow{3}{*}{$0-5$} & $0-5 \mathrm{~mm}$ & $67(51.9)$ & $10(40.0)$ & $77(50.0)$ & \multirow{3}{*}{0.049} \\
\hline & $6-14 \mathrm{~mm}$ & $52(40.3)$ & $9(36.0)$ & $61(39.6)$ & \\
\hline & $\geq 15 \mathrm{~mm}$ & $10(7.8)$ & $6(24.0)$ & $16(10.4)$ & \\
\hline \multirow{3}{*}{$6-18$} & $0-5 \mathrm{~mm}$ & $288(50.1)$ & $11(42.3)$ & $299(49.8)$ & \multirow{3}{*}{0.595} \\
\hline & $6-14 \mathrm{~mm}$ & $176(30.6)$ & $8(30.8)$ & $184(30.6)$ & \\
\hline & $\geq 15 \mathrm{~mm}$ & $111(19.3)$ & $7(26.9)$ & $118(19.6)$ & \\
\hline \multirow{3}{*}{$19-64$} & $0-5 \mathrm{~mm}$ & $441(30.2)$ & $6(17.6)$ & $447(29.9)$ & \multirow{3}{*}{0.028} \\
\hline & $6-14 \mathrm{~mm}$ & $485(33.2)$ & $8(23.5)$ & $493(33.0)$ & \\
\hline & $\geq 15 \mathrm{~mm}$ & $534(36.6)$ & $20(58.8)$ & $554(37.1)$ & \\
\hline \multirow{3}{*}{$65+$} & $0-5 \mathrm{~mm}$ & $40(62.5)$ & 0 & $40(60.6)$ & \multirow{3}{*}{-} \\
\hline & $6-14 \mathrm{~mm}$ & $10(15.6)$ & 0 & $10(15.2)$ & \\
\hline & $\geq 15 \mathrm{~mm}$ & $14(21.9)$ & $2(100.0)$ & $16(24.2)$ & \\
\hline \multirow{3}{*}{ Total } & $0-5 \mathrm{~mm}$ & $836(37.5)$ & $27(31.0)$ & $863(37.3)$ & \multirow{3}{*}{0.124} \\
\hline & $6-14 \mathrm{~mm}$ & $723(32.5)$ & $25(28.7)$ & $748(32.3)$ & \\
\hline & $\geq 15 \mathrm{~mm}$ & $669(30.0)$ & $35(40.3)$ & $704(30.4)$ & \\
\hline \multicolumn{6}{|c|}{ Without $B C G$ vaccine } \\
\hline \multirow{3}{*}{$0-5$} & $0-5 \mathrm{~mm}$ & $498(95.0)$ & $515(95.2)$ & $1,032(95.1)$ & \multirow{3}{*}{0.141} \\
\hline & $6-9 \mathrm{~mm}$ & $9(1.7)$ & $3(0.6)$ & $12(1.1)$ & \\
\hline & $\geq 10 \mathrm{~mm}$ & $17(3.2)$ & $23(4.3)$ & $40(3.8)$ & \\
\hline \multirow{3}{*}{$6-18$} & $0-5 \mathrm{~mm}$ & $409(76.7)$ & $34(49.3)$ & $443(73.6)$ & \multirow{3}{*}{$<0.001$} \\
\hline & $6-9 \mathrm{~mm}$ & $34(6.4)$ & $3(4.3)$ & $37(6.1)$ & \\
\hline & $\geq 10 \mathrm{~mm}$ & $90(16.9)$ & $32(46.4)$ & $122(20.3)$ & \\
\hline \multirow{3}{*}{$19-64$} & $0-5 \mathrm{~mm}$ & $421(41.1)$ & 48 (43.2) & $469(41.3)$ & \multirow{3}{*}{0.179} \\
\hline & $6-9 \mathrm{~mm}$ & $76(7.4)$ & $3(2.7)$ & $79(7.0)$ & \\
\hline & $\geq 10 \mathrm{~mm}$ & $528(51.5)$ & $60(54.1)$ & $588(51.8)$ & \\
\hline \multirow{3}{*}{$65+$} & $0-5 \mathrm{~mm}$ & $71(54.6)$ & $4(57.1)$ & $75(54.7)$ & \multirow{3}{*}{0.380} \\
\hline & $6-9 \mathrm{~mm}$ & $5(3.9)$ & $1(14.3)$ & $6(4.4)$ & \\
\hline & $\geq 10 \mathrm{~mm}$ & $54(41.5)$ & $2(28.6)$ & $56(40.9)$ & \\
\hline \multirow{3}{*}{ Total } & $0-5 \mathrm{~mm}$ & $1,399(63.2)$ & $601(82.5)$ & $2,000(68.0)$ & \multirow{3}{*}{$<0.001$} \\
\hline & $6-9 \mathrm{~mm}$ & $124(5.6)$ & $10(1.4)$ & $134(4.6)$ & \\
\hline & $\geq 10 \mathrm{~mm}$ & $689(31.1)$ & $117(16.1)$ & $806(27.4)$ & \\
\hline
\end{tabular}

aPercentage of column, ${ }^{\mathrm{b}} \mathrm{Chi}$ square test

previous BCG vaccination, or a cross-reaction to nontuberculous mycobacteria. Guidelines by the American Thoracic Society warn against taking former BCG vaccination into consideration when interpreting a TST reaction (16). For PPD specificity in BCG vaccinated people is between $65-70 \%$ due to the fact that the antigen used exists in BCG vaccine's origin (17). Besides, PPD sensitivity in culture-confirmed TB patients is between 75-90\% (18).

It was determined in our study that in the last two years (2014-2015) more PPD tests have been applied than in the years 2012-2013 at Hatay TD. PPD tests applied to Syrian refugees indicate a gradual increase throughout the period 2012-2015. Civil wars may also invite the international spread of infectious diseases and other public health concerns, which similarly lead to decline in living standards and generalized discontent (19). Syrian refugees generally live in crowded and unsanitary conditions, which may lead to the spread of respiratory infections. Especially in Syrian refugees, currently, multidrug-resistant tuberculosis appears to be the most frequently recorded diagnosis among the reemerging infections (20). Therefore, it appears as expected situation that the number of PPD increased in Hatay in pursuit of monitoring tuberculosis and detecting LTBIs among both Turks and Syrian refugees.

Significant differences were found during our research in the age distribution among Turks and Syrian refugees who were applied PPD. $68.7 \%$ of Syrian refugees fall into the $0-5$ age group. It is also reported by other studies that the demographic age structure of Syrian refugees seems to be young. It was asserted by Cookson et al. research conducted in Jordan that children of the 0-14 age group constitute $45 \%$ of Syrian refugees (21). 
Significant differences in terms of BCG scar were determined during our research and it turned out that $87.3 \%$ of the refugees do not have any BCG scar. Evaluating each age group one by one, it appears that the number of BCG scars was observed to be less among refugees within all age groups but $65+$. The fact that the number of people in the $65+$ age group was very small (10 persons) might have eliminated the BCG scar difference within this age group. The rarity of BCG scar availability among refugees gives rise to the thought that vaccination might have been insufficient not only during the war but also during the pre-war period. Tuberculosis care in Syria was integrated into the healthcare system nationwide with specialty TB treatment facilities located in each governorate, including Aleppo and Homs, areas badly destroyed by the conflict. As the conflict escalated, health infrastructure has been destroyed, drug supply chains have been interrupted, and healthcare workers have fled; all negatively impacting TB diagnosis and treatment efforts in Syria $(21,23)$.

In other respects, $94 \%$ of the refugees in the $0-5$ age group do not have BCG scar. That is why the $0-5$ age group was big in numbers, more PPD tests were applied to this age group. The American Academy of Pediatrics recommends the application of sequential testing for children below the age of five in order to diagnose LTBI (24). Another recommendation concerning the use of IGRA remarks that it could be used for BCG vaccinated children older than five years and for children without BCG vaccine if their probability of coming again for TST evaluation is low.

It was stated in Cookson et al. cross-sectional study about Syrian refugees and TB prevalence conducted in Jordan that high TB rates were found among Syrian refugees through active screening and will probably persist as the Syrian crisis continues; it stated that TB rates among displaced persons are high, but increased detection is possible (21).

Regarding the interpretation of positive reactions based on PPD evaluations according to our research results: positive reactions developed in people with BCG scars, $30.0 \%$ of them were Turks and $40.3 \%$ Syrian refugees; while there was no statistical difference found between the nationalities. It was surmised that less positive reactions developed in Turks because the average age of Turks was higher than of the refugees, since it is known that positivity of the skin test after BCG vaccination decreases with time after vaccination and depends on the age when vaccinated (22). A meta-analysis study investigating the impact of BCG vaccine on TDT remarks that vaccine-related responses decrease after 15 years from BCG vaccination and there is higher possibility that responses indicating $\geq 15 \mathrm{~mm}$ might be linked to tuberculosis infection (6). The result obtained by our study that refugees from the $0-5,19-64$ and $65+$ age groups with BCG scars have more positive reactions in statistical terms makes us think that they may have more contact with TB cases. In the study conducted in Istanbul on 1,213 children 3-48 months old who were BCG vaccinated positive contact history was found to be higher for the ones with $\geq 15 \mathrm{~mm}$ diameter of induration (25). A similar result was reported by a study conducted in Botswana on 3-60 months old children as well (26).

In our study, the $0-5$ age group appears to represent the lowest positive reaction rates and the 19-64 age group appears to represent the highest rate among Turks and refugees without BCG scar. The positive reaction rate is $3.2 \%$ among Turks without vaccine and $4.3 \%$ among refugees of the $0-5$ age group, and it is $51.5 \%$ among Turks without vaccine and 54.1\% among refugees of the 19-64 age group. Moreover, more positive reactions developed among refugees (46.4\%) than Turks (16.9\%) in the 6-18 age group. These findings reveal the idea that TB prevalence is higher within the 19-64 age group among people without vaccine of both nationalities but is lower within the 6-18 age group in refugees. They also point out that LTBI risk factors appear to be lower in the $0-5$ age group than other age groups among both nationalities.

The predictive value of the test will also depend on the prevalence of TB infection in particular population (27). TST has a higher positive predictive value when applied to children with risk factors for LTBI (28). Nonetheless, screening for LTBI in persons or groups who are healthy and have a low risk of progressing to active disease is not appropriate, since the positive predictive value of LTBI testing is low and the risks of treatment can outweigh potential benefits (29). Therefore, epidemiological and clinical results should also be taken into account concerning the risk of LTBI and developing the disease for individuals with positive reaction, and a detailed examination must be made (30). To exclude active TB prior to starting treatment for LTBI, most countries (62\%) used a combination of clinical screening for TB symptoms and a chest X-ray; this is consistent with WHO recommendations. Further 24 countries used these methods but supplemented them with additional diagnostic tests including smear microscopy, culture and molecular testing. The remaining countries used only clinical symptoms to exclude active TB (1).

Finally, in our study ARTIs were calculated and trends were evaluated based on age groups for people without vaccine of both nationalities for the period 2012-2015. The ARTI trends are a critical indicator for progress, or lack thereof, in tuberculosis control in a community (31). ARTI Rate of Change reviewing the change over time indicates the success of TB control programme. A positive ARTI rate of change means ARTI has decreased and ARTI rate of change is expected to be more than $5 \%$. More than $10 \%$ decrease occurs in the regions where TB control methods are sufficient, while this decrease remains below $5 \%$ in inadequate regions (32, 33).

In our study, ARTIs within the $0-5$ age group were $0.2 \%, 1.0 \%$, $1.3 \%$ and $1.4 \%$ among Turks and 2.3\%, 0.3\%, 2.4\% among Syrian refugees (except 2012). A progressive increase was determined among Turks from this age group, as the first two years showing a greater increase, while among Syrian refugees there was found first a rapid decline and then a rapid upsurge. ARTI was found as $0.48 \%$ by the study of Haghdoost et al. conducted in Iran between 2012-13 on 6-9 years old children; $0.34 \%$ by the study of Dubuis et al. conducted among 6-7 years old Afghan children in 2000; $1.7 \%$ by the study of Kolappan et al. conducted in India among 1-9 years old children in 2000 (34-36).

ARTIs within the 6-18 age group were 1.1\%, 2.0\%, 1.7\% and $1.5 \%$ among Turks and $8.5 \%, 6.6 \%, 7.3 \%$, and $2.4 \%$ among the refugees, respectively. ARTIs were found to be very high among Syrian refugees from this age groups compared to Turks. Firstly, a significant increase during the first two years and then a gradual decline was detected among Turks. As for Syrian refugees, a high decrease was observed within the first three years and then a rapid decline was observed in the fourth year among Syrian refugees.

ARTIs within the 19-64 age group were $2.0 \%, 2.3 \%, 1.3 \%$ and $1.7 \%$ among Turks and 1.8\%, 4.4\%, 2.4\% and 1.0\% among the refugees, respectively. Initially, an increase during the first two 
years and then a significant decline and fluctuation were observed for both Turks and refugees within this age group.

ARTIs within the $65+$ age group were $0.7 \%, 0.7 \%, 0.6 \%, 0.8 \%$ among Turks and $0.9 \%$ among the refugees in 2013. Comparing to the other age groups, ARTIs were lower among both Turks and refugees and did not indicate a significant change over the years.

\section{CONCLUSION}

Among Turks and Syrian refugees without BCG vaccine, the $0-5$ age group represents the lowest rate of positive PPD reaction and the 19-64 age group represents the highest rate. More positive PPD reactions developed in Syrian refugees compared to Turks within the 0-5, 19-64 and 65+ age groups among people with BCG vaccine and within the $6-18$ age group among people lacking BCG vaccine. On the other hand, higher ARTI rates were detected among Syrian refugees than Turks, which was found more significant within the $6-18$ age group. ARTIs among Turks within all age groups demonstrated a significant increase between the years 2012-2013, except for the 65+ age group. The question whether the increase in ARTI rates among Turks is related to the massive migration of Syrian refugees to Hatay after Syrian civil war should necessarily be investigated through other studies.

\section{Conflict of Interests}

None declared

\section{REFERENCES}

1. World Health Organization. Global tuberculosis report 2015. Geneva: WHO; 2015.

2. Getahun H, Matteelli A, Chaisson RE, Raviglione M. Latent Mycobacterium tuberculosis infection. N Eng J Med. 2015;372(22):2127-35.

3. Borgdorff MW. Annual risk of tuberculosis infection-time for an update? Bull World Health Org. 2002;80(6):501-2.

4. World Health Organization. Guidelines on the management of latent tuberculosis infection. Geneva: World Health Organization; 2015.

5. Pai M, Denkinger CM, Kik SV, Rangaka MX, Zwerling A, Oxlade O, et al. Gamma interferon release assays for detection of Mycobacterium tuberculosis infection. Clin Microbiol Rev. 2014;27(1):3-20.

6. Wang L, Turner MO, Elwood RK, Schulzer M, FitzGerald JM. A metaanalysis of the effect of Bacille Calmette Guérin vaccination on tuberculin skin test measurements. Thorax. 2002;57(9):804-9.

7. Akdag R, editor. Tuberculosis diagnosis and treatment guidelines 2011. Ankara: Basak Matbaacilik ve Tanitim Hizmetleri; 2011. (In Turkish.)

8. Republic of Turkey, Ministry of Health, Department of Tuberculosis. Reference book for the control of tuberculosis in Turkey. Ankara: Rekmay; 2003.

9. Chee CB, Soh CH, Boudville IC, Chor SS, Wang YT. Interpretation of the tuberculin skin test in Mycobacterium bovis BCG-vaccinated Singaporean schoolchildren. Am J Respir Crit Care Med. 2001;164(6):958-61.

10. Kritzinger FE, den Boon S, Verver S, Enarson DA, Lombard CJ, Borgdorff MW, et al. No decrease in annual risk of tuberculosis infection in endemic area in Cape Town, South Africa. Trop Med Int Health. 2009;14(2):13642.

11. Demir T. Epidemiology of tuberculosis. In: Tuberculosis Symposium in Adult and Child; 1999 Apr 30; Istanbul, Turkey. p. 9-13. (In Turkish.)

12. Turkish Statistical Institute. Address Based Population Registration System. Hatay population 2015 [Internet]. [cited 2018 Nov 2]. Available from: https://biruni.tuik.gov.tr/medas/?kn=95\&locale=tr. (In Turkish.)

13. Population of Syrian refugees in Hatay [Internet]. [cited 2018 Nov 2]. Available from: http://www.haberler.com/hatay-valisi-topaca-1-5-milyonnufuslu-kentimizde-8186628-haberi. (In Turkish.)

14. Rieder H. Annual risk of infection with Mycobacterium tuberculosis. Eur Respir J. 2005;25(1):181-5.
15. Garyfalia V, Irini G, Vasilios S, Konstantinos G. Annual risk of tuberculosis infection in hellenic air force recruits. Open Respir Med J. 2013;7:77-82.

16. American Thoracic Society. Targeted tuberculin testing and treatment of latent tuberculosis infection. MMWR Recomm Rep. 2000 Jun 9;49(RR6):1-51.

17. Schluger NW. Advances in the diagnosis of latent tuberculosis infection. Semin Respir Crit Care Med. 2013;34(1):60-6.

18. Herrera V, Perry S, Parsonnet J, Banaei N. Clinical application and limitations of interferon-gamma release assays for the diagnosis of latent tuberculosis infection. Clin Infect Dis. 2011;52(8):1031-7.

19. Ghobarah HA, Huth P, Russett B. Civil wars kill and maim people-long after the shooting stops. Am Polit Sci Rev. 2003; 97(2):189-202.

20. Doganay M, Demiraslan H. Refugees of the Syrian civil war: impact on reemerging infections, health services, and biosecurity in Turkey. Health Secur. 2016 Jul-Aug;14(4):220-5.

21. Cookson ST, Abaza H, Clarke KR, Burton A, Sabrah NA, Rumman KA, et al. "Impact of and response to increased tuberculosis prevalence among Syrian refugees compared with Jordanian tuberculosis prevalence: case study of a tuberculosis public health strategy". Confl Health. 2015 May 18;9:18. doi: 10.1186/s13031-015-0044-7.

22. Verbon A, Cobelens FG. Indications for, and the significance of, the tuberculin test in the Netherlands. Ned Tijdschr Geneeskd. 2003 Mar 22;147(12):539-43. (In Dutch.)

23. UN News. Syria experiencing critical shortage in medicines - WHO [Internet]. UN; 2012 [cited 2018 Nov 2]. Available from: https://news. un.org/en/story/2012/08/417182-syria-experiencing-critical-shortagemedicines-who.

24. Tuberculosis. In: Pickering LK, Baker CJ, Kimberlin DW, Long SS, editors. Red book: 2012 report of the Committee on Infectious Diseases. Elk Grove Village: American Academy of Pediatrics; 2012. p. 736-59.

25. Gökçay G, Partalcı A, Baş F, Neyzi O. Tuberculin reactivity in young children following neonatal BCG vaccination. J Trop Pediatr. 2000 Feb;46(1):51-2.

26. Tuberculin skin test survey in a pediatric population with high BCG vaccination coverage - Botswana, 1996. MMWR Morb Mortal Wkly Rep. 1997 Sep 12;46(36):846-51.

27. Huebner RE, Schein MF, Bass JB, Jr. The tuberculin skin test. Clin Infect Dis. 1993;17(6):968-75.

28. Starke JR; Committee on Infectious Diseases. Interferon-gamma release assays for diagnosis of tuberculosis infection and disease in children. Pediatrics. 2014 Dec;134(6):e1763-73.

29. Landry J, Menzies D. Preventive chemotherapy. Where has it got us? Where to go next? Int J Tuberc Lung Dis. 2008;12(12):1352-64.

30. Beser E. The prevalence of pulmonary tuberculosis using different methods in group screenings. East Afr Med J. 1993;70(12):768-71.

31. Shanaube K, Sismanidis C, Ayles H, Beyers N, Schaap A, Lawrence $\mathrm{KA}$, et al. Annual risk of tuberculous infection using different methods in communities with a high prevalence of TB and HIV in Zambia and South Africa. PLoS One. 2009 Nov 13;4(11):e7749. doi: 10.1371/journal. pone.0007749.

32. Styblo K. Epidemiology of tuberculosis. Sel Pap R Neth Tuberc Assoc. 1991;24:1-136.

33. Cauthen GM, Pio A, ten Dam HG. Annual risk of tuberculous infection. WHO; 1988.

34. Haghdoost AA, Afshari M, Baneshi MR, Gouya MM, Nasehi M, Movahednia M. Estimating the annual risk of tuberculosis infection and disease in southeast of Iran using the bayesian mixture method. Iran Red Crescent Med J. 2014 Sep 5;16(9):e15308. doi: 10.5812/ircmj.15308.

35. Dubuis M, Fiekert K, Johnston M, Neuenschwander BE, Rieder HL. A tuberculin skin test survey among Afghan children in Kabul. Int J Tuberc Lung Dis. 2004;8(9):1065-72.

36. Kolappan C, Gopi PG, Subramani R, Chadha VK, Kumar P, Prasad VV, et al. Estimation of annual risk of tuberculosis infection (ARTI) among children aged 1-9 years in the south zone of India. Int J Tuberc Lung Dis. 2004;8(4):418-23.

Received December 14, 2016 Accepted in revised form November 2, 2018 